
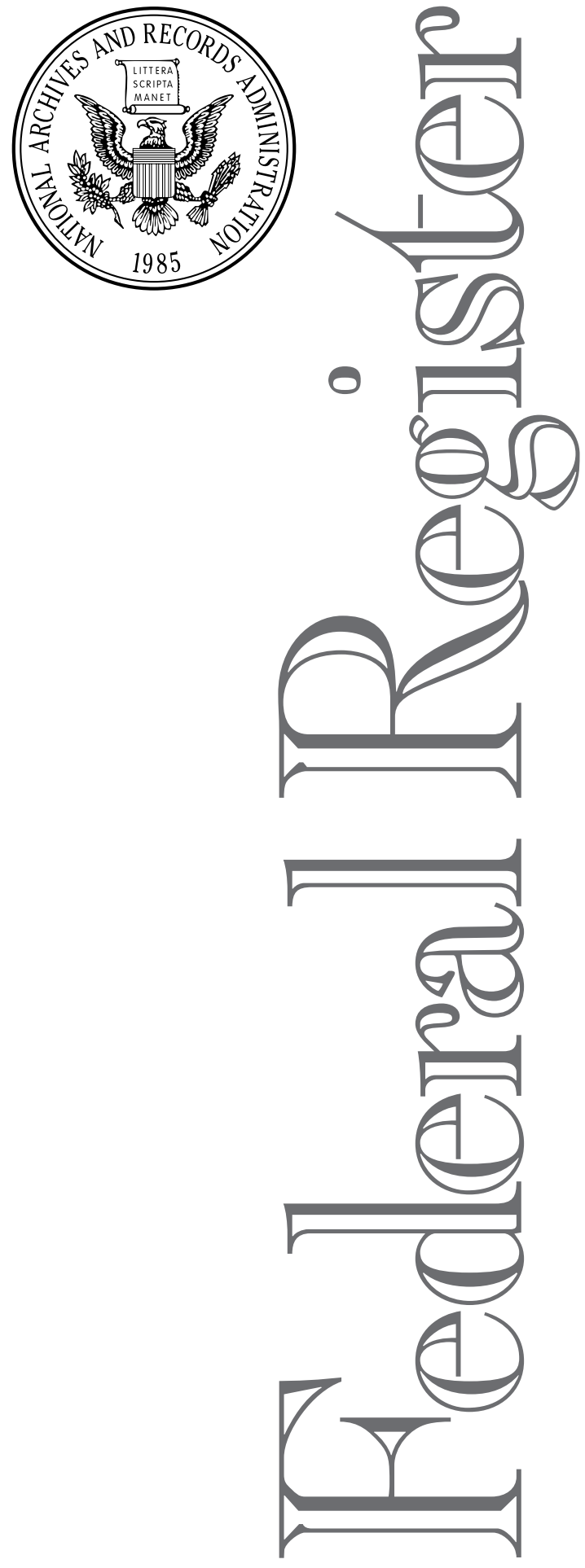

Wednesday,

May 6, 2009

\section{Part V}

\section{Department of Health and Human Services}

Centers for Medicare \& Medicaid Services

42 CFR Parts 431, 433, 440, et al. Medicaid Program; Health Care-Related Taxes; Medicaid Program: Rescission of School-Based Services Final Rule, Outpatient Services Definition Final Rule, and Partial Rescission of Case Management Services Interim Final Rule; Proposed Rules 


\section{DEPARTMENT OF HEALTH AND HUMAN SERVICES}

\section{Centers for Medicare \& Medicaid Services}

\section{CFR Part 433}

[CMS-2275-P2]

RIN 0938-AP74

\section{Medicaid Program; Health Care- Related Taxes}

AGENCY: Centers for Medicare \& Medicaid Services (CMS), HHS. ACTION: Proposed rule; delay of enforcement.

SUMmARY: This proposed rule would delay enforcement of certain portions of the final rule entitled "Medicaid Program; Health Care-Related Taxes" from the expiration of a Congressional moratorium on enforcement on July 1, 2009 until June 30, 2010. That final rule revised the threshold levels under the regulatory indirect guarantee hold harmless arrangement test to reflect the provisions of the Tax Relief and Health Care Act of 2006, amended the definition of the "class of managed care organization services," and removed obsolete transition period regulatory language. These changes would not be affected by this delay of enforcement. The final rule also clarified the standard for determining the existence of a hold harmless arrangement under the positive correlation test, Medicaid payment test, and the guarantee test. This proposed rule would delay enforcement of these latter provisions, concerning hold harmless arrangements, for 1 year.

DATES: Comment Period. To be assured consideration, comments must be received at one of the addresses provided below, no later than 5 p.m. on June 1, 2009.

ADDRESSES: In commenting, please refer to file code CMS-2275-P2. Because of staff and resource limitations, we cannot accept comments by facsimile (FAX) transmission.

You may submit comments in one of four ways (please choose only one of the ways listed):

1. Electronically. You may submit electronic comments on this regulation to http://www.regulations.gov. Follow the instructions for "Comment or Submission" and enter the file code to find the document accepting comments.

2. By regular mail. You may mail written comments (one original and two copies) to the following address ONLY: Centers for Medicare \& Medicaid Services, Department of Health and
Human Services, Attention: CMS-2275P2, P.O. Box 8010, Baltimore, MD 21244-8010.

Please allow sufficient time for mailed comments to be received before the close of the comment period.

3. By express or overnight mail. You may send written comments (one original and two copies) to the following address ONLY: Centers for Medicare \& Medicaid Services, Department of Health and Human Services, Attention: CMS-2275-P2, Mail Stop C4-26-05, 7500 Security Boulevard, Baltimore, MD 21244-8010.

4. By hand or courier. If you prefer, you may deliver (by hand or courier) your written comments (one original and two copies) before the close of the comment period to either of the following addresses:

a. Room 445-G, Hubert H. Humphrey Building, 200 Independence Avenue, SW., Washington, DC 20201. (Because access to the interior of the $\mathrm{HHH}$ Building is not readily available to persons without Federal Government identification, commenters are encouraged to leave their comments in the CMS drop slots located in the main lobby of the building. A stampin clock is available for persons wishing to retain a proof of filing by stamping in and retaining an extra copy of the comments being filed.)

b. 7500 Security Boulevard, Baltimore, MD 21244-1850. If you intend to deliver your comments to the Baltimore address, please call telephone number (410) 786-9994 in advance to schedule your arrival with one of our staff members.

Comments mailed to the addresses indicated as appropriate for hand or courier delivery may be delayed and received after the comment period.

FOR FURTHER INFORMATION CONTACT: Lisa Parker, (410) 786-4665.

\section{SUPPLEMENTARY INFORMATION:}

\section{Background}

Section 1903(w) of the Social Security Act (the Act) provides for a reduction of federal Medicaid funding based on State health care-related taxes unless those taxes are imposed on a permissible class of health care services; broad based, applying to all providers within a class; uniform, such that all providers within a class must be taxed at the same rate; and are not part of hold harmless arrangements in which collected taxes are returned, whether directly or indirectly. A similar hold harmless restriction applies to provider-related donations. Section 1903(w)(3)(E) of the Act specifies that the Secretary shall approve broad based (and uniformity) waiver applications if the net impact of the health care-related tax is generally redistributive and the amount of the tax is not directly correlated to Medicaid payments. The broad based and uniformity requirements are waivable through a statistical test that measures the degree to which the Medicaid program incurs a greater tax burden than if these requirements were met. The permissible class of health care services and hold harmless requirements cannot be waived. The statute and Federal regulation identify 19 permissible classes of health care items or services that States can tax without triggering a penalty against Medicaid expenditures.

On February 22, 2008 we published a final rule entitled, "Medicaid Program; Health Care-Related Taxes”' (73 FR 9685). This final rule amended provisions governing the determination of whether health care provider taxes or donations constitute "hold harmless" arrangements under which provider tax revenues are repaid, altered the indirect guarantee threshold test, revised the definition of the "class of managed care provider," and deleted certain obsolete provisions. The rule reduced the indirect guarantee threshold test in order to reduce the threshold level of permissible taxes on health care providers for the period of January 1 , 2008, through September 30, 2011, as required by the Tax Relief and Health Care Act of 2006 (Pub. L. 109-432).

The February 22, 2008 final rule was scheduled to become effective on April 22, 2008. However, section 7001(a)(3)(C) of the Supplemental Appropriations Act of 2008, Public Law No. 110-252, imposed a partial moratorium until April 1, 2009, prohibiting CMS from taking any action to implement any provisions of the final rule that are more restrictive than the provisions in effect on February 21, 2008, with the exception of the change in the definition of the class of managed care provider and the statutorily-required change to the indirect guarantee threshold test. This moratorium was extended by section 5003(a) of the American Recovery and Reinvestment Act of 2009, Public Law No. 111-5, until July 1, 2009. Although not subject to the moratorium, the change in the definition of the "class of managed care provider" is subject to a delayed compliance date of October 1, 2009, in order to permit States time to implement necessary changes.

\section{Provisions of the Proposed Rule}

We propose to delay the enforcement of the changes made in the February 22, 2008 final rule to the hold harmless 
tests under $\S$ 433.54(c) and 433.68(f), other than the statutorily-required change to the indirect guarantee threshold level, until June 30, 2010. As discussed above, this portion of the regulation has been the subject of Congressional moratoria and has not yet been implemented by CMS. This additional time is necessary to determine whether additional clarification or guidance would be necessary or helpful to our State partners. It is our understanding that certain States are concerned that the regulatory language is overbroad or unclear. We believe the delay will permit more time to obtain information about the potential impact of the rule and alternative approaches, and to ensure appropriate implementation of the statutory restrictions on provider taxes and donations.

\section{Response to Comments}

Because of the large number of public comments we normally receive on

Federal Register documents, we are not able to acknowledge or respond to them individually. We will consider all comments we receive by the date and time specified in the DATES section of this preamble, and, when we proceed with a subsequent document, we will respond to the comments in the preamble to that document.

\section{Collection of Information Requirements}

This document does not impose information collection and recordkeeping requirements. Consequently, it need not be reviewed by the Office of Management and Budget under the authority of the Paperwork Reduction Act of 1995.

\section{Regulatory Impact Analysis}

\section{A. Overall Impact}

We have examined the impact of this proposed rule as required by Executive Order 12866, the Congressional Review Act, the Regulatory Flexibility Act (RFA), section 1102(b) of the Social Security Act, the Unfunded Mandates Reform Act of 1995 (Pub. L. 104-4), and Executive Order 13132 on Federalism. Executive Order 12866 (as amended) directs agencies to assess all costs and benefits of all available regulatory alternatives and, if regulation is necessary, to select regulatory approaches that maximize net benefits (including potential economic, environmental, public health and safety effects, distributive impacts, and equity). A regulatory impact analysis (RIA) must be prepared for major rules with economically significant effects (\$100 million or more in any 1 year).

The final rule on health-care related taxes was estimated to result in savings to the Federal government, by reducing its financial participation in the

Medicaid program for amounts in excess of the tax-related threshold, with corresponding responses by States that would partially offset these savings. Specifically, the RIA for the final rule estimated that Federal Medicaid outlays would be reduced by $\$ 85$ million in FY 2008, and \$115 million in FY 2009 through FY 2011. These savings resulted directly from applying the language in the Tax Relief and Health Care Act of 2006 to reduce the maximum threshold on exclusion of health care related taxes from 6 percent to 5.5 percent of net patient revenue. We do not propose to delay application of this reduced threshold, which is already in effect. Accordingly, we believe that the proposed delay would not have any substantial economic effect, and that this proposed rule is not "economically significant" under E.O. 12866 or "major" under the Congressional Review Act.

The RFA requires agencies to analyze options for regulatory relief of small entities if proposed or final rules have a "significant economic impact on a substantial number of small entities." For purposes of the RFA, small entities include small businesses, nonprofit organizations, and small governmental jurisdictions, including school districts. "Small" governmental jurisdictions are defined as having a population of less than fifty thousand. Individuals and States are not included in the definition of a small entity. In the final rule on health care related taxes, we analyzed potential impacts on small entities that might result from the change in the exclusion threshold. Some effects (reduced tax burden) were likely to be positive and some (reductions in State reimbursement rates) could be either positive or negative. All of these effects would depend on future State decisions on taxation and reimbursement that could not be predicted and would in any event be indirect effects rather than the direct result of that rule. Regardless, because this rule does not propose to delay the change in the exclusion threshold, we conclude, and the Secretary certifies, that this proposed rule would not have a significant effect on a substantial number of small entities.

In addition, section 1102(b) of the Act requires us to prepare a regulatory impact analysis if a rule may have a significant impact on the operations of a substantial number of small rural hospitals. This analysis must conform to the provisions of section 604 of the RFA. For purposes of section 1102(b) of the Act, we define a small rural hospital as a hospital that is located outside of a Metropolitan Statistical Area and has fewer than 100 beds. Our analysis of the final rule concluded that it would have had no significant direct effect on a substantial number of these hospitals. This proposed rule does not impose any new requirements. Accordingly, we are not preparing an analysis for section 1102(b) of the Act because we have determined, and the Secretary certifies, that this proposed rule would not have a direct impact on the operations of a substantial number of small rural hospitals.

Section 202 of the Unfunded Mandates Reform Act of 1995 also requires that agencies assess anticipated costs and benefits before issuing any rule whose mandates require spending in any 1 year of \$100 million in 1995 dollars, updated annually for inflation. That threshold level is currently approximately $\$ 130$ million. This proposed rule contains no mandates that will impose spending costs on State, local, or tribal governments in the aggregate, or by the private sector, of $\$ 130$ million.

Executive Order 13132 on Federalism establishes certain requirements that an agency must meet when it promulgates a proposed rule (and subsequent final rule) that imposes substantial direct requirements on State and local governments, preempts State law, or otherwise has Federalism implications. EO 13132 focuses on the roles and responsibilities of different levels of government, and requires Federal deference to State policy-making discretion when States make decisions about the uses of their own funds or otherwise make State-level decisions. The original final rule, while limiting Federal funding, did not circumscribe the States' authority to make policy decisions regarding taxes and reimbursement. This proposed rule will likewise not have a substantial effect on State or local government policy discretion.

\section{B. Anticipated Effects}

As discussed in the final rule published February 22, 2008, States had a number of options open to them in addressing any reduction in Federal Financial Participation (FFP). They could restructure State spending and shift funds among programs, raise funds through increases in other forms of generally applicable tax revenue increases, or reduce reimbursement to the tax-paying health care providers. 
Presumably most of those States have already made those decisions. Although the delay proposed in this rule will not affect the tax threshold, it will provide some relief to States in making other adjustments.

\section{Alternatives}

We welcome comments not only on the proposed delay in enforcement, but also on alternatives that may more constructively address the underlying problems and their likely impacts on States and other stakeholders.

In accordance with the provisions of Executive Order 12866, this regulation was reviewed by the Office of Management and Budget.

(Catalog of Federal Domestic Assistance Program No. 93.778, Medical Assistance Program)

Dated: April 30, 2009.

Charlene Frizzera,

Acting Administrator, Centers for Medicare $\&$ Medicaid Services.

Approved: May 1, 2009.

Kathleen Sebelius,

Secretary.

[FR Doc. E9-10460 Filed 5-1-09; 4:15 pm] BILLING CODE 4120-01-P

\section{DEPARTMENT OF HEALTH AND HUMAN SERVICES}

\section{Centers for Medicare \& Medicaid Services}

\section{CFR Parts 431, 433, 440 and 441 \\ [CMS-2287-P2; CMS-2213-P2; CMS 2237-P] \\ RIN 0938-AP75}

\section{Medicaid Program: Rescission of School-Based Services Final Rule, Outpatient Services Definition Final Rule, and Partial Rescission of Case Management Services Interim Final Rule}

AGENCY: Centers for Medicare \& Medicaid Services (CMS), HHS. ACTION: Proposed rule.

SUMMARY: This rule proposes to rescind the December 28, 2007 final rule entitled "Elimination of Reimbursement Under Medicaid for School

Administration Expenditures and Costs Related to Transportation of School-Age Children Between Home and School"; the November 7, 2008 final rule entitled "Clarification of Outpatient Hospital Facility (Including Outpatient Hospital Clinic) Services Definition"; and certain provisions of the December 4, 2007 interim final rule with comment period entitled "Optional State Plan Case
Management Services." These regulations have been the subject of Congressional moratoria and have not yet been implemented (or, with respect to case management interim final rule, have only been partially implemented) by CMS. In light of concerns raised about the adverse effects that could result from these regulations, in particular the potential restrictions on services available to beneficiaries, potential deleterious effect on state partners in the economic downturn, and the lack of clear evidence demonstrating that the approaches taken in the regulations are warranted, CMS is proposing to rescind the two final rules in full, and to partially rescind the interim final rule. Rescinding these provisions will permit further opportunity to determine the best approach to further the objectives of the Medicaid program in providing necessary health benefits coverage to needy individuals.

DATES: To be assured consideration, comments must be received at one of the addresses provided below, no later than 5 p.m. on June 1, 2009.

ADDRESSES: In commenting, please refer to file code CMS-2287-P2. Because of staff and resource limitations, we cannot accept comments by facsimile (FAX) transmission.

You may submit comments in one of four ways (please choose only one of the ways listed):

1. Electronically. You may submit electronic comments on this regulation to http://www.regulations.gov. Follow the instructions under the "More Search Options" tab.

2. By regular mail. You may mail written comments to the following address ONLY: Centers for Medicare \& Medicaid Services, Department of Health and Human Services, Attention: CMS-2287-P2, P.O. Box 8010,

Baltimore, MD 21244-8010.

Please allow sufficient time for mailed comments to be received before the close of the comment period.

3. By express or overnight mail. You may send written comments to the following address ONLY: Centers for Medicare \& Medicaid Services, Department of Health and Human Services, Attention: CMS-2287-P2, Mail Stop C4-26-05, 7500 Security Boulevard, Baltimore, MD 21244-1850.

4. By hand or courier. If you prefer, you may deliver (by hand or courier) your written comments before the close of the comment period to either of the following addresses:

a. For delivery in Washington, DCCenters for Medicare \& Medicaid Services, Department of Health and
Human Services, Room 445-G, Hubert H. Humphrey Building, 200 Independence Avenue, SW., Washington, DC 20201.

(Because access to the interior of the Hubert H. Humphrey Building is not readily available to persons without Federal government identification, commenters are encouraged to leave their comments in the CMS drop slots located in the main lobby of the building. A stamp-in clock is available for persons wishing to retain a proof of filing by stamping in and retaining an extra copy of the comments being filed.)

b. For delivery in Baltimore, MDCenters for Medicare \& Medicaid Services, Department of Health and Human Services, 7500 Security Boulevard, Baltimore, MD 21244-1850.

If you intend to deliver your comments to the Baltimore address, please call telephone number (410) 7869994 in advance to schedule your arrival with one of our staff members.

Comments mailed to the addresses indicated as appropriate for hand or courier delivery may be delayed and received after the comment period. FOR FURTHER INFORMATION CONTACT: LISA Parker, (410) 786-4665.

SUPPLEMENTARY INFORMATION: Inspection of Public Comments: All comments received before the close of the comment period are available for viewing by the public, including any personally identifiable or confidential business information that is included in a comment. We post all comments received before the close of the comment period on the following Web site as soon as possible after they have been received: $h t t p: / /$

www.regulations.gov. Follow the search instructions on that Web site to view public comments.

Comments received timely will also be available for public inspection as they are received, generally beginning approximately 3 weeks after publication of a document, at the headquarters of the Centers for Medicare \& Medicaid Services, 7500 Security Boulevard, Baltimore, Maryland 21244, Monday through Friday of each week from 8:30 a.m. to 4 p.m. To schedule an appointment to view public comments, phone 1-800-743-3951.

\section{Background}

A. Elimination of Reimbursement Under Medicaid for School Administration Expenditures and Costs Related to Transportation of School-Age Children Between Home and School

Under the Medicaid program, Federal payment is available for the costs of administrative activities as found 